\title{
The Neurochemical Effects of Prazosin Treatment on Fear Circuitry in a Rat Traumatic Stress Model
}

\author{
Sema Ketenci ${ }^{1}$, Nazife Gökçe Acet ${ }^{2}$, Gökçe Elif Sarıdoğan ${ }^{1,3}$, Banu Aydın ${ }^{4}$, Hülya Cabadak ${ }^{4}$, \\ Mehmet Zafer Gören ${ }^{1}$ \\ ${ }^{1}$ Department of Medical Pharmacology, Marmara University School of Medicine, ${ }^{2}$ Department of Medical Pharmacology, Medeniyet University, \\ Faculty of Medicine, ${ }^{3}$ Department of Psychiatry, Erenköy Mental Health and Research Hospital, ${ }^{4}$ Department of Biophysics, Marmara University, \\ Faculty of Medicine, Istanbul, Turkey
}

\begin{abstract}
Objective: The timing of administration of pharmacologic agents is crucial in traumatic stress since they can either potentiate the original fear memory or may cause fear extinction depending on the phase of fear conditioning. Brain noradrenergic system has a role in fear conditioning. Data regarding the role of prazosin in traumatic stress are controversial.

Methods: In this study, we examined the effects of prazosin and the noradrenergic system in fear conditioning in a predator stress rat model. We evaluated the direct or indirect effects of stress and prazosin on noradrenaline (NA), gamma-aminobuytyric acid (GABA), glutamate, glycine levels and choline esterase activity in the amygdaloid complex, the dorsal hippocampus, the prefrontal cortex and the rostral pons.

Results: Our results demonstrated that prazosin might alleviate defensive behaviors and traumatic stress symptoms when given during the traumatic cue presentation in the stressed rats. However prazosin administration resulted in higher anxiety levels in non stressed rats when the neutral cue was presented.

Conclusion: Prazosin should be used in PTSD with caution because prazosin might exacerbate anxiety in non-traumatized subjects. However prazosin might as well alleviate stress responses very effectively. Stress induced changes included increased NA and GABA levels in the amygdaloid complex in our study, attributing noradrenaline a possible inhibitory role on fear acquisition. Acetylcholine also has a role in memory modulation in the brain. We also demonstrated increased choline esterase acitivity. Cholinergic modulation might be another target for indirect prazosin action which needs to be further studied.
\end{abstract}

KEY WORDS: Noradrenalline; Rostral pons; Cholinergic; Gamma-aminobuytyric acid; Glutamic acid; Glycine.

\section{INTRODUCTION}

Diagnostic and Statistical Manual of Mental Disorders, the 5th edition (DSM-5) defines the post-traumatic stress disorder (PTSD) as a multifaceted disorder that occurs as consequence of an intense and/or life-threatening trauma [1]. It was stated that the DSM-5 introduced a new symptom cluster constituted of intrusions, avoidance, negative alterations in cognition, mood and changes in arousal and

Received: August 7, 2019/ Revised: September 3, 2019

Accepted: September 6, 2019

Address for correspondence: Mehmet Zafer Gören

Department of Medical Pharmacology, Marmara University

School of Medicine, Başıüyük Maltepe, Istanbul 34672, Turkey

E-mail: zgoren@gmail.com

ORCID: https://orcid.org/0000-0002-8800-4043 reactivity. Collectively, self destructive behaviors were also included. Upon its inclusion to the DSM III in 1980, the disease became the third most commonly diagnosed disorder by psychologists [2].

In the literature, there is a vast number of behavioral and clinical and experimental studies where many agents were administered shortly after trauma or during memory reconsolidation, but none became to be an effective agent to date [3]. In these studies, prazosin, an old drug, that has been used to lower blood pressure, an alpha1-adrenoreceptor blocker, has been found effective in improving PTSD-related sleep symptoms, hyper-arousal, global clinical status and overall PTSD symptom burden [4]. As the antidepressants were found useless in most chronic conditions, prazosin has been shown to be effective in treat-

(ㄷ) This is an Open-Access article distributed under the terms of the Creative Commons Attribution Non-Commercial License (http://creativecommons.org/licenses/by-nc/4.0) which permits unrestricted non-commercial use, distribution, and reproduction in any medium, provided the original work is properly cited. 
ing chronic PTSD cases [5].

Among the affected brain regions, the hippocampus seems to be disturbed by the high levels of circulating hormones and released neurotransmitters during stress that may affect the processing of the memories and eventually change the normal hippocampal functions, making the memories of traumatic events and nightmares to persist and even the memories can be processed incorrectly [6]. Central nucleus of the amygdala acts as the principal output nucleus of amygdala which is engaged by lateral nucleus, projecting to the hypothalamus and the brain stem to elucidate autonomic, endocrine, and behavioral responses associated with fear and anxiety [7]. It was also stated that amygdala orchestrates the interaction between the glucocorticoids and the noradrenaline (NA) in modulating the memory consolidation [8]. Both the central noradrenergic and the peripheral sympathetic systems function together in PTSD and numerous data supply the evidence that noradrenergic hyper-reactivity in patients with PTSD may be associated with the conditioned or sensitized responses to specific traumatic stimuli $[9,10]$. Stressful stimuli of many types produce marked increases in brain noradrenergic function. In an experimental study performed in rats using predator scent test that serves as an experimental model for PTSD, it was stated that NA levels increase in locus coeruleus (LC) in stressed rats [11]. The brain noradrenergic system is involved in mediating the fear conditioning $[12,13]$. It was stated in previous studies that neutral stimuli already paired with shock produced increases in brain NA metabolism and exhibit behavioral deficits similar to those elicited by the shock alone as well as increased firing rate of cells in the LC [12,14]. An intact noradrenergic system is required for the generation of fear-conditioned responses [12].

The aim of this study is to show the behavioral efficacy of prazosin in a rat model of PTSD induced by predator scent test using dirty cat litter. The changes in NA, glutamate, gamma-aminobuytyric acid (GABA), glycine and acetylcholine (ACh) esterase (AChE) activity in different brain regions related to the PTSD following the onset of stress were also demonstrated. Similarly, the effect of prazosin on the neurotransmitters was also examined.

\section{MEHODS}

\section{Animals and Experimental Conditions}

An approval from the institutional ethical committee was obtained before making the experiments (MUHDEK approval no: 72.2015.mar). Sprague-Dawley rats of both sexes weighing 250 - 300 g supplied from Marmara University Animal Center (DEHAMER) were used in the study. The rats were habituated to the housing conditions for 10 days with a reversed 12 hours light/dark cycle (the lights turned on at $8 \mathrm{PM})$ at $21 \pm 3^{\circ} \mathrm{C}$ and $50 \pm 5 \%$ humidity with unlimited access to standard rat chow and water. All experiments were performed in the dark phase at 10:00 AM using a dim red light source. The rats were housed in groups where each group had 4 rats per cage. The rats were $3-4$ months of age. The males and females were kept in cages in the same room.

\section{Predator Scent Test}

The urine of a male cat was chosen as the predator scent, for that reason dirty cat litter was used. The cat litter had been used for 2 days by the same cat and had been sifted for stools as described previously [15-17]. The stress paradigm was produced by placing the rats on $125 \mathrm{ml}$ of dirty cat litter for 10 minutes in a Plexiglas cage $(30 \times 30 \times$ $40 \mathrm{~cm}$ ). The control animals were exposed to identical fresh, unused litter for the same amount of time. The rats were subjected to clean cat litter as a situational reminder 1 week after the onset of the stress. The behavioral experiments were recorded using an overhead video camera and behavioral parameters were scored from the recordings later. The injections were given 10 minutes before the predator test.

\section{Drugs and Solutions}

Several doses were tried but treatment groups received intraperitoneal (ip) injections of prazosin $(16 \mathrm{mg} / \mathrm{kg}$; Sigma, St. Louis, MO, USA) suspended in physiological saline. This dose was human effective doses. The higher doses produced autonomic changes and the rats displayed a mute state (data not presented). Control group received physiological saline injections.

\section{Elevated Plus Maze Experiments}

The rats were placed on an elevated plus maze for $5 \mathrm{mi}-$ nutes immediately after they had been subjected to the sit- 
uational reminder. The elevated plus maze had two open $(50 \times 10 \mathrm{~cm})$ and two closed $(50 \times 10 \mathrm{~cm})$ arms. The closed arms were surrounded by $40 \mathrm{~cm}$ long walls. The height of the maze was $50 \mathrm{~cm}$ from the ground. The labyrinth was cleaned with $5 \%$ alcohol solution before the rats were placed on it. Each rat was placed in the central square of the plus maze facing the open arms. An arm entry was defined as an animal entering the arm with all four feet and the number of entries into open and enclosed arms was scored as described previously [18].

The cumulative freezing time, a fear parameter, was also recorded and evaluated. Freezing time was defined as the time that rats spend the time in immobile behaviour except for respiration during test period (300 seconds). It was obtained by substracting the time in motion from the duration of the test period. The motions are head or body grooming, sniffing, rearing, walking. The motion durations were noted and freezing time was calculated. The number of fecal pellet counts were also recorded during the time spent on the maze. Upon completion of the experiments the rats were sacrificed with a high dose of pentobarbital and the whole brain regions were kept at $-80^{\circ} \mathrm{C}$ for and ELISA methods. All animals were used ELISA analyses.

\section{Tissue Preparation and ELISA Measurements}

The frozen brains were sliced according to the coordinates stated in Rat Brain Atlas [19]. Anteroposterior planes used for removing the frontal cortex, the dorsal hippocampus and the amygdaloid complex were located between $13.20-11.20 \mathrm{~mm}, 6.70-4.70 \mathrm{~mm}$ and $7.20-$ $5.70 \mathrm{~mm}$ anterior to the inter-aural line, respectively. The interaural line was accepted as $9.00 \mathrm{~mm}$ posterior to the

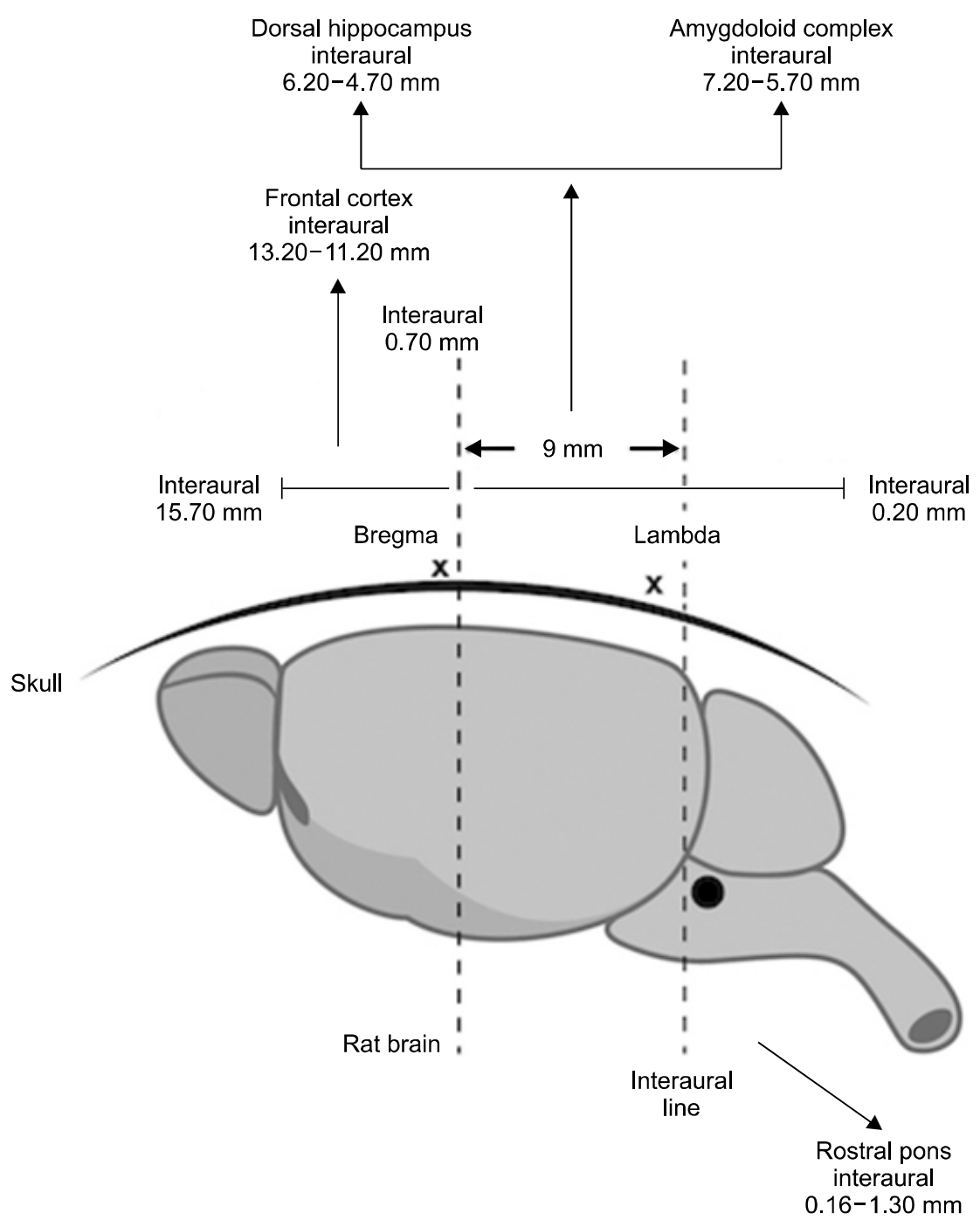

Fig. 1. The schematic illustration of micro-dissections. There are 2 reference points on the rat skull namely; the bregma and the lambda. The inter-aural line falls $0.3 \mathrm{~mm}$ posterior to the lambda. The distance from bregma and interaural line is $9 \mathrm{~mm}$ in a $260 \mathrm{~g}$ Wistar rat. The coronal sections from Rat Brain Atlas [19] were used to dissect the tissues in the slices shown. The sections start at $15.70 \mathrm{~mm}$ and ends at $0.20 \mathrm{~mm}$ anterior to the interaural line. The regions were removed according to sagittal thickness of the inter-aural coordinates and coronal depths from the surface of brains. 
tip of the brain as indicated. The dark colored locus coeruleus found in the rostral pons of the brain stem $(0.16-$ $1.30 \mathrm{~mm}$ posterior to the inter-aural line) were also removed. Figure 1 shows the schematic illustration of the micro-dissections of the brain regions. The tissues were ground using T25 Ultraturrax homogenizer (Janke and Kunkel IKA-Labortechnik, Staufen, Germany). The protein content of the crude homogenates was determined by Lowry Method to normalize the protein contents [20]. The values corresponding to $500 \mu \mathrm{g}$ of protein in standard Lowry calculations were expressed as $\mathrm{nmol} / \mathrm{mg}$. The GABA, glutamate, glycine, NA levels were measured by using rat ELISA kits according to the manufacturer's instructions (The Smart ${ }^{\mathrm{TM}}$ BCA Protein Kit; iNtRON Biotechnology, Beverly, MA, USA). AChE activity was measured by the
Acetylcholinesterase Assay Kit (DACE-100, QuantiChrom ${ }^{\text {TM }}$; BioAssay Systems, Hayward, CA,USA).

\section{Statistical Analysis}

One-way Analysis of Variance followed by Tukey's post-hoc test were used for the analyses of 3 or more groups. Two-way Analysis of variance and Bonferroni post-test was also used where the stress is being one factor and the treatment being another. Statistical significance was investigated at $p<0.05$ level. All data are expressed as mean \pm standard error of the mean.
$\mathbf{A}$

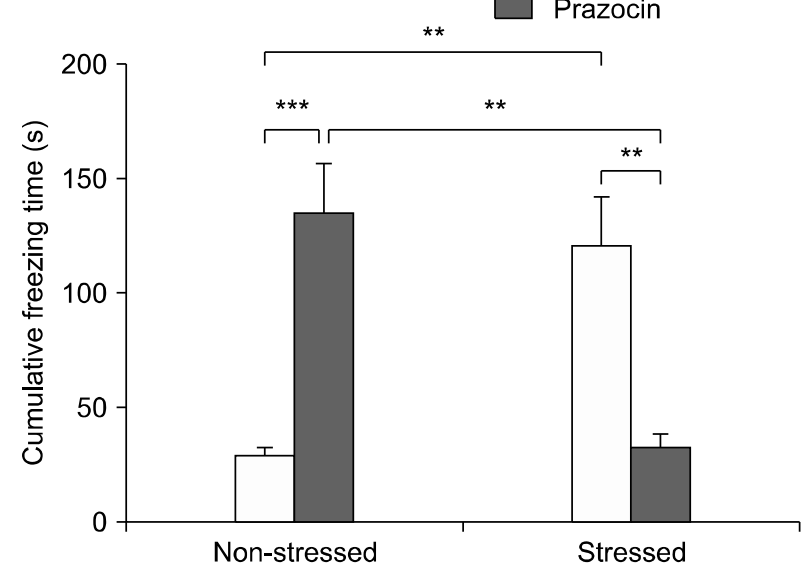

C

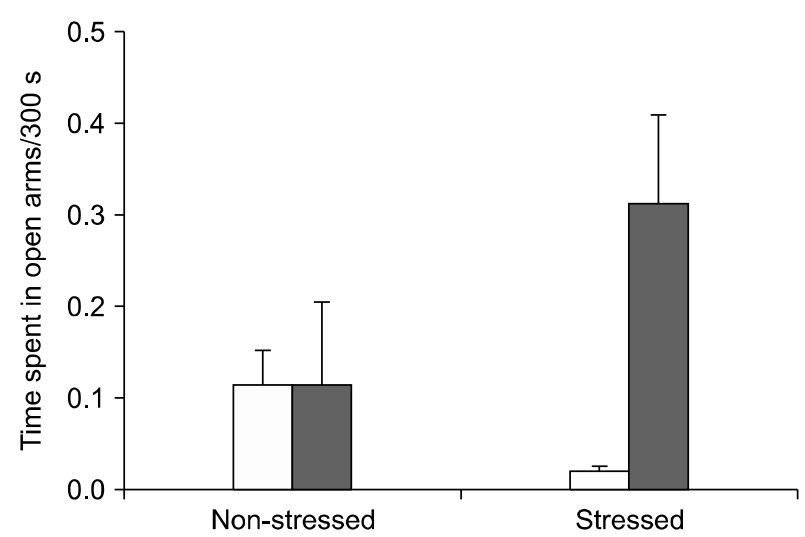

B $\quad \square$ Physiological saline

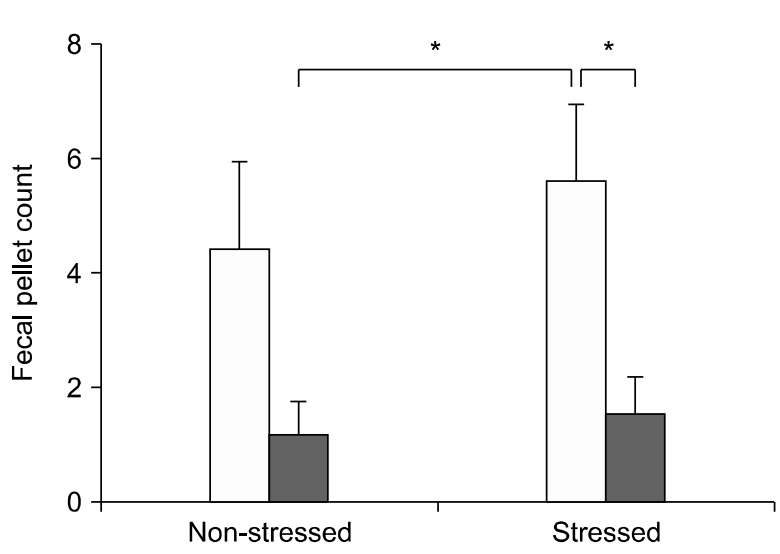

D $\square$ Physiological saline

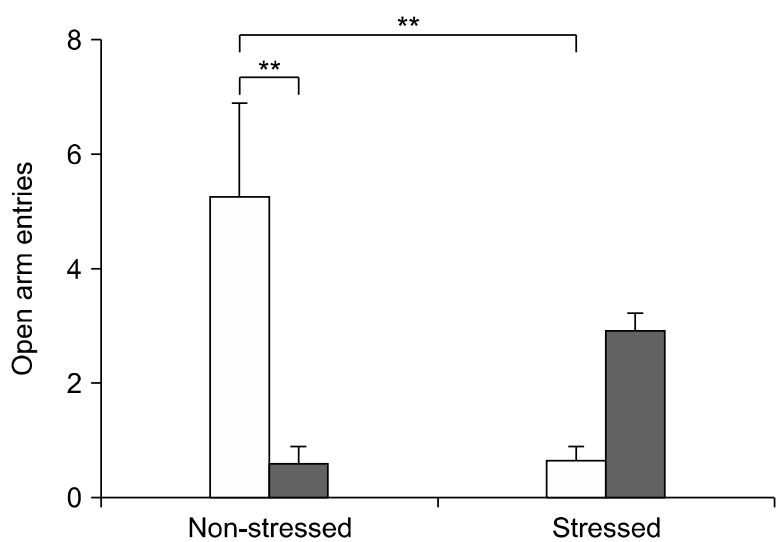

Fig. 2. The effects of physiological saline (intraperitoneal, ip) or prazosin $(16 \mathrm{mg} / \mathrm{kg}$, ip) on (A) cumulative freezing time $(\mathrm{s} ; \mathrm{F}=11.62, \mathrm{df}=3, p<$ 0.0001), (B) fecal pellet count ( $\mathrm{F}=4.661, \mathrm{df}=3, p<0.001)$, (C) time spent in open arms $/ 300 \mathrm{~s}(\mathrm{~F}=2.274, \mathrm{df}=3, p>0.05)$, (D) open arm entries $(\mathrm{F}=8.162, \mathrm{df}=3, p<0.001)$ in stressed and non-stressed rats $(\mathrm{n}=8$ per group).

${ }^{*} p<0.05 ;{ }^{* *} p<0.01 ;{ }^{* * *} p<0.001$ (Tukey's post-hoc test). 


\section{RESULTS}

\section{The Analysis of the Behavioral Data}

The cumulative freezing times recorded for 10 minutes on the elevated plus maze upon exposure to the trauma reminder (the clean cat litter) were $119.3 \pm 22.4$ seconds and $28.3 \pm 3.8$ seconds in the stressed and non-stressed control rats, respectively. One-way analysis of variance produced a significant difference between groups $(\mathrm{df}=3$, $\mathrm{F}=11.62, p<0.0001)$. When the Tukey's multiple comparison test was applied to the data, it showed that the trauma increased the freezing time in the stressed rats treated with physiological saline (Fig. 2A). Prazosin treatment also increased the duration of freezing time in nonstressed controls (Fig. 2A). Collectively, prazosin treatment decreased the freezing time in the stressed rats.

Table 1. The effect of physiological saline or prazosin treatment on noradrenalline, GABA, glycine, glutamate levels and acetylcholine esterase activity in different brain regions of rats subjected to stress

\begin{tabular}{|c|c|c|c|c|c|c|}
\hline \multirow{2}{*}{$\begin{array}{c}\mathrm{NTs} \\
\text { (ng/mg } \\
\text { tissue) }\end{array}$} & \multirow{2}{*}{$\begin{array}{l}\text { Brain } \\
\text { regions }\end{array}$} & \multicolumn{2}{|c|}{ Stress $(-)$} & \multicolumn{2}{|c|}{ Stress $(+)$} & \multirow{2}{*}{$\begin{array}{l}\text { Two-way ANOVA statistics } \\
\text { (source of variation) }\end{array}$} \\
\hline & & Physiological saline & Prazosin & Physiological saline & Prazosin & \\
\hline \multirow[t]{4}{*}{ NA } & $A C$ & $3.07 \pm 0.24$ & $3.70 \pm 0.30$ & $3.88 \pm 0.22^{* *}$ & $3.68 \pm 0.40$ & $\begin{array}{l}\text { Stress }(\mathrm{df}=1, \mathrm{f}=6.652, p<0.05) \\
\text { Interaction }(\mathrm{df}=1, \mathrm{f}=7.986, p<0.05)\end{array}$ \\
\hline & $\mathrm{DH}$ & $2.83 \pm 0.13$ & $2.88 \pm 0.3$ & $3.31 \pm 0.19$ & $2.80 \pm 0.50$ & $\begin{array}{l}\text { Stress }(\mathrm{df}=1, \mathrm{f}=1.058, p>0.05) \\
\text { Treatment }(\mathrm{df}=1, \mathrm{f}=1.401, p>0.05)\end{array}$ \\
\hline & PFC & $2.63 \pm 0.4$ & $3.1 \pm 0.2$ & $2.79 \pm 0.60$ & $2.85 \pm 0.50$ & $\begin{array}{l}\text { Stress }(\mathrm{df}=1, \mathrm{f}=0.02554, p>0.05) \\
\text { Treatment }(\mathrm{df}=1, \mathrm{f}=1.265, p>0.05)\end{array}$ \\
\hline & $\mathrm{RP}$ & $7.39 \pm 0.23$ & $3.77 \pm 0.4$ & $18.89 \pm 3.36^{*}$ & $3.50 \pm 0.20$ & Interaction $(\mathrm{df}=1, \mathrm{f}=6.697, p<0.05)$ \\
\hline \multirow[t]{4}{*}{ GABA } & $\mathrm{AC}$ & $3.07 \pm 0.24$ & $3.70 \pm 0.22$ & $3.89 \pm 0.23^{*}$ & $3.68 \pm 0.18$ & Interaction $(\mathrm{df}=1, \mathrm{f}=4.447, p<0.05)$ \\
\hline & $\mathrm{DH}$ & $122.90 \pm 2.83$ & $119.60 \pm 17.10$ & $126.30 \pm 7.61$ & $112.60 \pm 13.60$ & $\begin{array}{l}\text { Stress }(\mathrm{df}=1, \mathrm{f}=1.472, p>0.05) \\
\text { Treatment }(\mathrm{df}=1, \mathrm{f}=0.5429, p>0.05)\end{array}$ \\
\hline & PFC & $103.10 \pm 10.60$ & $124.70 \pm 8.10$ & $110.50 \pm 11.60$ & $113.60 \pm 4.80$ & $\begin{array}{l}\text { Treatment }(\mathrm{df}=1, \mathrm{f}=8.300, p<0.01) \\
\text { Interaction }(\mathrm{df}=1, \mathrm{f}=4.681, p<0.05)\end{array}$ \\
\hline & $\mathrm{RP}$ & $136.20 \pm 6.58$ & $157.40 \pm 10.10$ & $129.30 \pm 11.10$ & $135.10 \pm 12.60$ & $\begin{array}{l}\text { Stress }(\mathrm{df}=1, \mathrm{f}=4.258, p>0.05) \\
\text { Treatment }(\mathrm{df}=1, \mathrm{f}=3.683, p>0.05)\end{array}$ \\
\hline \multirow[t]{4}{*}{ Gly } & $\mathrm{AC}$ & $4.03 \pm 0.44$ & $4.60 \pm 1.20$ & $4.64 \pm 0.57$ & $4.30 \pm 0.90$ & $\begin{array}{l}\text { Stress }(\mathrm{df}=1, \mathrm{f}=0.0953, p>0.05) \\
\text { Treatment }(\mathrm{df}=1, \mathrm{f}=0.0569, p>0.05)\end{array}$ \\
\hline & $\mathrm{DH}$ & $5.08 \pm 0.84$ & $3.90 \pm 1.30$ & $4.67 \pm 0.61$ & $4.60 \pm 0.60$ & $\begin{array}{l}\text { Stress }(\mathrm{df}=1, \mathrm{f}=0.0802, p>0.05) \\
\text { Treatment }(\mathrm{df}=1, \mathrm{f}=0.9751, p>0.05)\end{array}$ \\
\hline & PFC & $4.53 \pm 1.00$ & $4.15 \pm 1.10$ & $3.99 \pm 0.70$ & $4.44 \pm 0.40$ & $\begin{array}{l}\text { Stress }(\mathrm{df}=1, \mathrm{f}=0.0992, p>0.05) \\
\text { Treatment }(\mathrm{df}=1, \mathrm{f}=0.0058, p>0.05)\end{array}$ \\
\hline & $\mathrm{RP}$ & $4.26 \pm 0.50$ & $3.30 \pm 0.40$ & $4.22 \pm 0.38$ & $4.00 \pm 0.80$ & $\begin{array}{l}\text { Stress }(\mathrm{df}=1, \mathrm{f}=0.6570, p>0.05) \\
\text { Treatment }(\mathrm{df}=1, \mathrm{f}=2.176, p>0.05)\end{array}$ \\
\hline \multirow[t]{4}{*}{ Glu } & $A C$ & $32.22 \pm 2.79$ & $36.00 \pm 4.80$ & $31.81 \pm 2.28$ & $38.60 \pm 8.50$ & $\begin{array}{l}\text { Stress }(\mathrm{df}=1, \mathrm{f}=0.1402, p>0.05) \\
\text { Treatment }(\mathrm{df}=1, \mathrm{f}=3.263, p>0.05)\end{array}$ \\
\hline & $\mathrm{DH}$ & $31.30 \pm 2.57$ & $40.20 \pm 10.10$ & $32.91 \pm 3.05$ & $33.40 \pm 6.20$ & $\begin{array}{l}\text { Stress }(\mathrm{df}=1, \mathrm{f}=0.4574, p>0.05) \\
\text { Treatment }(\mathrm{df}=1, \mathrm{f}=0.1865, p>0.05)\end{array}$ \\
\hline & PFC & $35.07 \pm 8.40$ & $45.25 \pm 7.90$ & $35.08 \pm 7.20$ & $36.48 \pm 8.50$ & $\begin{array}{l}\text { Stress }(\mathrm{df}=1, \mathrm{f}=0.1309, p>0.05) \\
\text { Treatment }(\mathrm{df}=1, \mathrm{f}=2.291, p>0.05)\end{array}$ \\
\hline & RP & $31.45 \pm 1.99$ & $37.00 \pm 4.60$ & $36.14 \pm 2.29$ & $40.80 \pm 12.10$ & $\begin{array}{l}\text { Stress }(\mathrm{df}=1, \mathrm{f}=0.2541, p>0.05) \\
\text { Treatment }(\mathrm{df}=1, \mathrm{f}=0.1633, p>0.05)\end{array}$ \\
\hline \multirow[t]{4}{*}{ AChE A } & AC & $2.76 \pm 0.31$ & $185.70 \pm 62.00$ & $31.49 \pm 8.36$ & $145.10 \pm 62.00$ & Treatment $(\mathrm{df}=1, \mathrm{f}=9.948, p<0.05)$ \\
\hline & $\mathrm{DH}$ & $29.76 \pm 19.07$ & $255.00 \pm 50.00^{*}$ & $3.87 \pm 1.00$ & $174.00 \pm 50.00$ & $\begin{array}{l}\text { Stress }(\mathrm{df}=1, \mathrm{f}=3.693, p>0.05) \\
\text { Treatment }(\mathrm{df}=1, \mathrm{f}=44.84, p>0.05) \\
\text { Interaction }(\mathrm{df}=1, \mathrm{f}=3.066, p>0.05)\end{array}$ \\
\hline & PFC & $107.50 \pm 16.10$ & $847.80 \pm 69.10$ & $548.6 \pm 98.80$ & $648.03 \pm 76.80$ & Treatment $(\mathrm{df}=1, \mathrm{f}=6.803, p<0.05)$ \\
\hline & $\mathrm{RP}$ & $1.53 \pm 0.22$ & $39.10 \pm 10.00$ & $92.23 \pm 23.75$ & $175.00 \pm 74.00^{*}$ & $\begin{array}{l}\text { Stress }(\mathrm{df}=1, \mathrm{f}=9.134, p>0.05) \\
\text { Treatment }(\mathrm{df}=1, \mathrm{f}=2.578, p>0.05) \\
\text { Interaction }(\mathrm{df}=1, \mathrm{f}=0.3628, p>0.05)\end{array}$ \\
\hline
\end{tabular}

Values are presented as mean \pm standard error of the mean.

GABA, gamma aminobutyric acid; NTs, neurotransmitters; NA, noradrenalline; Gly, glycine; Glu, glutamate; AChE A, acetylcholine esterase activity; AC, amygdaloid complex; $\mathrm{DH}$, dorsal hippocampus; PFC, prefrontal cortex; RP, rostral pons.

${ }^{*} p<0.05$, Bonferroni post-test, significantly different from others. ${ }^{* *} p<0.01$, Bonferroni post-test, significantly different from others. 
Two-way ANOVA yielded an interaction $(\mathrm{df}=1, \mathrm{~F}=$ 34.47, $p<0.0001$ ) between trauma and treatment, where treatments produced significant differences in Bonferroni post-test $(p<0.001)$.

The fecal pellet count on the elevated plus maze were also recorded and produced significant difference (Fig. $2 \mathrm{~A} ; \mathrm{df}=3, \mathrm{~F}=4.661, p<0.05)$. The stressed rats treated with physiological saline produced more pellets than the stressed rats treated with prazosin or the non-stressed controls treated with prazosin (Fig. 2B). Two-way ANOVA showed that treatment is the source of variation $(\mathrm{df}=1, \mathrm{~F}=$ 13.37, $p<0.001$ ).

Although the ratio of time spent in the open arms to total duration on the maze (300 seconds) did not produce any statistical significance (Fig. 2C; $\mathrm{F}=2.274, \mathrm{df}=4, p>$ 0.05 ) but the open arm entries were significantly lower in the stressed rats treated with saline (Fig. 2D) where prazosin treatment reversed the decreased open arm entry $(\mathrm{F}=$ $8.162, \mathrm{df}=3, p<0.05)$. Prazosin itself also decreased the open arm entry in the non-stressed rats. Two-way ANOVA also yielded an interaction between trauma and treatment in terms of open arm entries $(\mathrm{df}=1, \mathrm{~F}=21.85$, $p<0.001)$ and Bonferroni post-test revealed that treatments were significantly different.

\section{The Comparison of ELISA Neurotransmitter Analyses in Different Brain Region Homogenates of the Stressed and the Non-stressed Rats}

NA levels were found to elevated in homogenates of tissues collected from the amygdaloid complex in rats subjected to predator scent (Table 1). Two-way analysis of variance showed that stress produced the variation $(\mathrm{df}=$ $1, f=7.986, p<0.05)$. There is an interaction between stress and treatments $(\mathrm{F}=6.652, \mathrm{df}=1, p<0.05)$. Bonferroni post-test yielded that saline treated rats were different from other groups $(p<0.01)$. NA levels in the prefrontal cortex and the dorsal hippocampus did not show any significant changes (Table 1).

GABA levels were increased in the stressed control rats. The levels increased from $3.07 \pm 0.24$ to $3.86 \pm 0.22$ $\mathrm{nmol} / \mathrm{mg}$ tissue (Table 1). Two-way ANOVA revealed that there is an interaction between stress and the treatment $(F=$ 4.447, $\mathrm{df}=1, p<0.05)$ and the saline treated traumatized rats were different from other groups $(p<0.05$; Table 1). In the prefrontal cortex homogenates, GABA measurements were found to be elevated in the stressed controls. Prazosin treatment was shown to be the source of variation as stated in Table 1 (df $=1, F=8.300, p<$ 0.01 ). Although an interaction between stress and treatment was detected $(\mathrm{F}=4.681, \mathrm{df}=1, p<0.05)$, Bonferroni post-test did not reveal any difference. GABA levels in the rostral pons were found to be statistically non-significant in different groups (Table 1). Glycine levels were not found to be different both in the stressed and non-stressed rats and prazosin tratment did not affect the levels in all 4 different brain regions.

Glutamate measurements also displayed a similar fashion as presented in Table 1. AChE activity has been found to be increased in response to prazosin treatment in the amygdaloid complex (Table 1; $\mathrm{F}=9.948, \mathrm{df}=1, p<$ 0.05). Similarly the enzyme activity was found to be increased in the prefrontal cortex in the prazosin treated rats (Table 1; $\mathrm{F}=6.803, \mathrm{df}=1, p<0.05$ ).

\section{DISCUSSION}

The first part of our study demonstrates that cat litter scent induced stress and resulted in higher cumulative freezing times and lower number of entries into the open arms of elevated plus maze in the stressed rats without prazosin injections. This finding is in accordance with the findings of the previous studies published from our laboratory $[11,21]$. On the other hand prazosin injections did not produce any significant difference in the total time spent on the open arms neither due to stress exposure nor due to treatments on the elevated plus maze. A PTSD experimental model that mimics the human situation caused by a single acute traumatic event, might well be translated to an animal model by using the methodology of Pavlovian fear conditioning. In Pavlovian fear conditioning, an aversive stimulus such as a foot shock or a loud noise is referred as an unconditioned stimulus (US) and a neutral stimulus such as a normal non-aversive tone that is paired with this aversive stimulus is called as the conditioned stimulus (CS). In our design we used the predator stress model. In this study, the clean cat litter was used as the CS and the dirty cat litter was used as the US. As the subject learns the association between these stimuli, CS may elicit defensive responses such as freezing [22-24]. Previous studies showed that stress due to predator threat elicits stress and increase freezing response. Freezing is a measurable universal reaction to stress 
$[25,26]$. Dirty cat litter exposure resulted in higher cumulative freezing times in our experiments indicating the model's ability to form traumatic stress. However prazosin injections produce increased freezing durations in non-stressed rats. In other words only clean cat litter presented subjects without any previous dirty cat litter exposure showed higher levels of stress with prazosin injections. This finding can be interpreted as: prazosin might possibly increase the stress when the subjects are not previously subjected to a stressful condition. This may be due to autonomic effects of the drug. Additionally, we also observed that prazosin injections 2 hours before the traumatic stress reminder in the stressed rats elicited an opposite effect, which is a significant decrease in the stress levels regarding the cumulative freezing times. Our previous study performed with $d$-cycloserine suggested that timing of drug administration in the traumatic stress can be critical since it might enhance either the stress related behavioral parameters or decrease the defensive behaviors depending on the time of administration in relation to the onset of the traumatic stress and the time and the number of stress reminder presentation [27]. We can also say that prazosin effects are not due to a consequence of a sedation or decrese in locomotor activity since a previous paper which studied the effect of prazosin on the recreational drug 3,4-methylenedioxymethamphetamine (MDMA, ecstasy) induced changes in locomotor activity showed that pre-treatment with systemic prazosin or microinjections into either the prefrontal cortex or ventral tegmental area completely blocked the locomotor stimulant effects of MDMA. However the control experiments showed that prazosin alone did not produce any change in the locomotor activity [28]. The timing of the drug is also critical, the drug can be given after stress exposure however we wanted to observe the pure physiopathological effects of prazosin.

It has been reported that benzodiazepines are ineffective for PTSD treatment and prevention [29]. A previous study also showed that alprazolam, a benzodiazepine when given immediately after stress exposure increases vulnerability to subsequent stress in an animal model of PTSD through interacting with the normal HPA-stress response [30].

According to our assumption that $\alpha_{1}$ antagonist may relieve the symptoms of PTSD we may think that $\alpha_{1}$ agonists may make the situation worse. However, making an ex- periment with $\alpha_{1}$ agonists is very difficult since it can generate overt sympathetic effects if given systemically. We can indirectly observe the effects of $\alpha_{1}$ agonists in a clinical trial where an SSRI and an SNRI were compared. In that study, sertraline (an SSRI) had a slightly better outcome than venlafaxine (an SNRI) on some of the secondary outcome measures [31]. Clonidine, an $\alpha_{2}$ agonist and an inhibitory receptor acts as a centrally acting sympatholytic agent can decrease the noradrenergic activity and it also has off-label use in PTSD especially for symptoms related to autonomic arousal and panic attacks [32]. It was also reviewed in a recent paper that there are no pharmacological preventive interventions for routine clinical practice. However, the use of hydrocortisone administration initiated within 12 hours post-trauma may be efficient. Propranolol, escitalopram, and benzodiazepines are not likely to reduce PTSD development. It was also recommended that benzodiazepines should be prescribed with caution in early post-trauma due to potential risk of increasing PTSD symptoms [33].

NA has been shown to play roles in the modulation of anxiety and fear memory in anxiety disorders including PTSD [34-37]. PTSD is characterized by exaggerated responsiveness of amygdala while the ventromedial prefrontal cortex and the regulation of amygdala by the hippocampus is also disrupted. Correspondingly, in PTSD the acquisition of fear responses is exaggerated and the reversal of these exaggerated fear responses cannot be easily mediated [38].

Pavlovian fear conditioning consists of different stages of fear learning. Acquisition refers to the initial fear learning by forming an association between the CS and the US. After this initial learning of fear, during consolidation phase, this fear memory becomes stable. After 24 hours, long term memory (LTM) can be tested and recalled solely with CS, leading to the retrieval of the fear memory which is the period that we tested in our study. Retrieval causes the fear memory to destabilize and re-consolidation is required to place it back in the LTM. Thus fear can be extinguished via a new learning process by weakening the association between the US and CS by presenting CS multiple times. This process is called as extinction learning and it is another learning that requires the consolidation of a new memory [39]. Pharmacological agents affect fear learning and act on each phase of fear learning differently and may have positive or negative effects in the clinical 
settings regarding the time of administration.

Prazosin is an antagonist at the alpha- 1 class sub-types of adrenergic receptors. Prazosin hydrocloride capsules are indicated for the treatment of hypertension, to lower blood pressure $[40,41]$. The drug has later been reported to reduce nightmares in PTSD. Many clinical studies of prazosin in the treatment of PTSD, including open-label and randomized controlled trials have confirmed the finding [42]. Although its major effect for PTSD was observed in veterans whom the drug was administered for hypertension, later studies focused on other symptoms related to NA, such as sleep dysregulation and hyper-vigilance, ending up with promising results [42].

Nevertheless, role of NA in the biological basis of fear memory during Pavlovian fear conditioning related disorders such as PTSD is not well assessed in the literature, targeting the specific stages of fear learning and the timing in disease progression. Even so, among the sub-types of noradrenergic class, beta and alpha- 2 adrenergic receptors received more attention than the alpha- 1 sub-type adrenergic receptors leaving the role of this class mainly as a question mark [43]. Alpha1-adrenergic receptors are likely to act on inhibitory or excitatory neurons on Lateral Amygdala (LA) in fear conditioning $[44,45]$. In response to aversive stimuli, LC fires NA containing outputs that reach $L A$, in a tonic and phasic manner $[46,47]$. A recent study by Lazzaro et al. [43] demonstrated that alpha1-adrenergic receptor antagonists, like prazosin and terazosin, appear to dis-inhibit plasticity in LA fear conditioning pathway by blocking the feed forward inhibition that powerfully regulates and limits fear conditioning pointing out that wide use of these agents might exacerbate fear related disorders by leading to stronger fear learning. In this experimental setting we demonstrated the changes in the amygdala however not in the LA. The tissue is very small and it is very difficult to separate and dissect the LA. Further studies that will be performed by using immunohistochemical staining methods can supply more information to the role of the LA.

On the other hand, prazosin treatment is known to enhance the extinction of fear responses which were supported by targeted cannulation experiments that indicated that the basolateral amygdala as a brain region for alpha-1 adrenergic receptor related NA actions on extinction [48]. We tested the defensive behaviors in stressed rats by presenting the clean cat litter in our experiments. Similarly stressed rats that received prazosin showed significantly decreased anxiety reactions since both number of entries into the open arms on the elevated plus maze increased however this was not found to be statistically significant. In our study prazosin injections before presenting the clean cat litter (CS) to the stressed rats resulted in an immediate decrease in the fear. In the previous studies, beta-adrenergic receptor blocker propranolol was also reported as an adrenergic modulator to treat PTSD symptoms similarly in clinical studies when administered after traumatic stress reminders [49-52].

We also evaluated the changes in fecal pellet number which is an indicator directly proportional to the stress levels. We observed an increased fecal pellet number in the stressed rats however this result was not significant. In addition, our results demonstrated that the rats treated with prazosin independent from stress, produced decreased amount of fecal pellets. This result is possibly due to a direct local autonomic effect of prazosin. Naitou et al. [53] suggested that alpha-1 adrenoceptors on sacral parasympathetic preganglionic neurons cause propulsive motility in the colorectum when stimulated with noradrenaline. Our findings is continuous with the results of Naitou et al. [53]'s study and suggest that prazosin decrease fecal pellet production by the blockade of alpha-1 adrenergic receptors possibly due to a similar colokinetic mechanism. However this finding needs to be further studied via local interventions.

In the last part of the study we investigated cat scent stress and prazosin effects on different brain regions involved in fear memory and in brain including the amygdaloid complex, the dorsal hippocampus, the prefrontal cortex and the rostral pons for NA circuitry. The amygdala is a key structure in the brain that receives the sensory inputs and gives the motor outputs to other structures $[24,54,55]$. Thus this region is the modulator of fear learning sharing data with other two basic structures in the system: prefrontal cortex and the hippocampus [56,57]. A heterogeneity of nuclei are located in the amygdala with different connections and neurochemical compositions $[46,58,59]$. Medial prefrontal cortex (mPFC) can regulate fear via projections to the basal and the lateral amygdala neurons which can respond to both to acquisition and extinction of fear. In addition, infralimbic region of $\mathrm{mPFC}$ plays a role in fear extinction [24,60-62]. There are also connections from the amygdala to the brain stem resulting 
in sympathetic nervous system activation by leading to release of adrenaline and NA throughout the body $[63,64]$. Rostral pons contains LC and is located in the brainstem. Noradrenergic neurons in the brain are abundantly located in the LC and this region gives projections to the areas such as the hippocampus, the amygdala, the thalamus and the prefrontal cortex that have roles in memory, emotionality, stress and fear circuits [65].

In our study, we observed that NA levels significantly increased in the amydala and the rostral pons in the stressed rats. Stress significantly increased GABA levels in the amygdaloid complex in rats receiving physiologic saline, possibly due to increased NA levels which can be attributed that the inhibitory nature of NA in the amygdala by increasing GABA levels. Previously alpha- 1 adrenergic receptors in the amygdala are well demonstrated to act to inhibit fear conditioning via stimulating miniature inhibitory post synaptic currents mediated by GABA, gating synaptic plasticity necessary for fear conditioning $[43,44,66]$.

We observed no significant changes in the glycine and the glutamate levels which were known to have crucial roles in fear learning and PTSD. $d$-cycloserin, which acts as a partial antagonist for glycine binding site on GluNR1 receptors, a type of NMDA receptor, has been shown to have roles both in consolidation of fear mainly by affecting the prefrontal cortex and fear extinction by facilitating the down-regulation of NMDA receptors for a new extinction learning in a traumatic stress model of predator stress formed with cat fur odor [27]. However, another neurotransmitter, $\mathrm{ACh}$, has also been shown to increase in stress and may affect the memory processes. ACh was indirectly measured via ACh esterase activity. The impact of stress on brain and the circuitry are complicated and cannot be attributed to one neurotransmitter. We observed that ACh esterase activity increased in the dorsal hippocampus in the non-stressed rats and in the rostral pons of the stressed rats in response to prazosin treatment. As prazosin treatment ameliorates the symptoms of stress, and it also suppresses the sympathetic activity. The cholinergic activity may be increased as an adaptive response to the antagonism of adrenergic system so that we observed the increased AChE levels. However, as our study demonstrated that prazosin might create a possible disposition to stress by increasing anxiety, if applied in non-traumatized subject, this may be explained with increased cholinergic activity. A cross-over placebo controlled trial for assessing the effects of scopolamine in affective disorders demonstrated that cholinergic muscarinic receptor blockade by scopolamine caused an effective and robust response to depressive symptomatology [67]. This may account for why prazosin treatment increases anxiety in the nonstressed rats. Aykaç et al. [21] reported that the expressions of $M_{2}, M_{3}$ and $M_{5}$ type muscarinic receptor proteins increased in the frontal cortex and $M_{4}$ subtype decreased in the hippocampal region where all muscarinic receptor sub-types decreased in the amygdaloid complex. We also demonstrated the roles of ACh, Glutamate and GABA in generating central cardiovascular effects through stimulation of amygdala. Amygdala produces stress responses through hypothalamus. We also demonstrated the roles of ACh, Glutamate and GABA in generating central cardiovascular effects through stimulation of amygdala. Amygdala produces stress responses through hypothalamus [68-70].

In conclusion, prazosin has long been recommended for nightmares and hyper-vigilance symptoms for clinical use in PTSD. However, our study demonstrates that prazosin might create a possible disposition to stress by increasing anxiety, if applied in non-traumatized subjects. In our study, the clean cat litter acts as a neutral stimulus and evoked defensive behaviors when prazosin was administered in non-traumatized rats. Possibly, prazosin seems to the decrease stress and defensive behaviors if administered before a traumatic stress reminder. Thus we recommend to use prazosin very cautiously in PTSD. However, prazosin might as well lead to increased anxiety if applied to non-stressed subjects possibly through cholinergic mechanisms. Stress induced changes including the increased NA and GABA levels in the amygdaloid complex may indicate presence of inhibitory modulatory effects of NA through GABA in the fear circuitry. ACh plays an important role in memory modulation throughout the brain and prazosin seems to increase the activity of AChE in different brain areas in the stressed and the non-stressed rats. Thus cholinergic modulation might be another target for indirect prazosin action which needs to be further evaluated.

\section{- Acknowledgments}

This study was supporrted by a grant supplied by Marmara University Research Fund (Project Grant \#: 


\section{SAG-C-DRP-130116-0003).}

- Conflicts of Interest

No potential conflict of interest relevant to this article was reported.

\section{Author Contributions}

Performed the experiments: Sema Ketenci, Nazife Gökçe Acet, Banu Aydın. Analyzed the results and conducted the project: Mehmet Zafer Gören, Gökçe Elif Sarıdoğan, and Hülya Cabadak.

\section{ORCID}

Sema Ketenci https://orcid.org/0000-0002-6695-7003 Nazife Gökçe Acet https://orcid.org/0000-0002-1625-3008 Gökçe Elif Sarıdoğan https://orcid.org/0000-0003-0049-2001 Banu Aydın https://orcid.org/0000-0002-3267-8620 Hülya Cabadak https://orcid.org/0000-0001-5757-2198 Mehmet Zafer Gören https://orcid.org/0000-0002-8800-4043

\section{REFERENCES}

1. American Psychiatric Association. Diagnostic and statistical manual of mental disorders: DSM-5. 5th ed. Arlington: American Psychiatric Association;2013.

2. Evans SC, Reed GM, Roberts MC, Esparza P, Watts AD, Correia JM, et al. Psychologists' perspectives on the diagnostic classification of mental disorders: results from the WHO-IUPsyS Global Survey. Int J Psychol 2013;48:177-193.

3. Anisman H, Hayley S, Kusnecov A. Posttraumatic stress disorder. In: Anisman H, Hayley S, Kusnecov A, editors. The immune system and mental health. Amsterdam:Academic Press;2018. p.335-365.

4. Manhapra A, Ralevski E, Petrakis IL. Is pretreatment blood pressure a marker of prazosin response in posttraumatic stress disorder with comorbid alcohol use disorder? Biol Psychiatry 2019;85:e11-e12.

5. Green B. Prazosin in the treatment of PTSD. J Psychiatr Pract 2014;20:253-259.

6. Meftahi G, Ghotbedin Z, Eslamizade MJ, Hosseinmardi N, Janahmadi M. Suppressive effects of resveratrol treatment on the intrinsic evoked excitability of CA1 pyramidal neurons. Cell J 2015;17:532-539.

7. Schafe GE, Nader K, Blair HT, LeDoux JE. Memory consolidation of Pavlovian fear conditioning: a cellular and molecular perspective. Trends Neurosci 2001;24:540-546.

8. McGaugh JL, Roozendaal B. Role of adrenal stress hormones in forming lasting memories in the brain. Curr Opin Neurobiol 2002;12:205-10.

9. Aston-Jones G, Shipley MT, Chouvet G, Ennis M, van Bockstaele E, Pieribone $\mathrm{V}$, et al. Afferent regulation of locus coeruleus neurons: anatomy, physiology and pharmacology. Prog Brain Res 1991;88:47-75.

10. Neumeister A, Daher RJ, Charney DS. Anxiety disorders: noradrenergic neurotransmission. In: Holsboer $F$, Ströhle $A$, Bilkei-Gorzo A, editors. Anxiety and anxiolytic drugs. Berlin: Springer-Verlag;2005. p.205-223.

11. Terzioğlu B, Kaleli M, Aydın B, Ketenci S, Cabadak H, Gören $\mathrm{MZ}$. Increased noradrenaline levels in the rostral pons can be reversed by $M 1$ antagonist in a rat model of post-traumatic stress disorder. Neurochem Res 2013;38:1726-1733.

12. Rasmussen K, Morilak DA, Jacobs BL. Single unit activity of locus coeruleus neurons in the freely moving cat. I. During naturalistic behaviors and in response to simple and complex stimuli. Brain Res 1986;371:324-334.

13. Charney DS, Deutch A. A functional neuroanatomy of anxiety and fear: implications for the pathophysiology and treatment of anxiety disorders. Crit Rev Neurobiol 1996;10:419-446.

14. Cassens G, Kuruc A, Roffman M, Orsulak PJ, Schildkraut JJ. Alterations in brain norepinephrine metabolism and behavior induced by environmental stimuli previously paired with inescapable shock. Behav Brain Res 1981;2:387-407.

15. Cohen H, Matar MA, Richter-Levin G, Zohar J. The contribution of an animal model toward uncovering biological risk factors for PTSD. Ann N Y Acad Sci 2006;1071:335-350.

16. Matar MA, Cohen H, Kaplan Z, Zohar J. The effect of early poststressor intervention with sertraline on behavioral responses in an animal model of post-traumatic stress disorder. Neuropsychopharmacology 2006;31:2610-2618.

17. Mazor A, Matar MA, Kaplan Z, Kozlovsky N, Zohar J, Cohen $\mathrm{H}$. Gender-related qualitative differences in baseline and post-stress anxiety responses are not reflected in the incidence of criterion-based PTSD-like behaviour patterns. World J Biol Psychiatry 2009;10:856-869.

18. Pellow S, Chopin P, File SE, Briley M. Validation of open: closed arm entries in an elevated plus-maze as a measure of anxiety in the rat. J Neurosci Methods 1985;14:149-167.

19. Paxinos G, Watson C. The rat brain: stereotaxic coordinates. 2nd ed. Sydney:Academic Press; 1986.

20. Lowry OH, Rosebrough NJ, Farr AL, Randall RJ. Protein measurement with the Folin phenol reagent. J Biol Chem 1951; 193:265-275.

21. Aykaç A, Aydın B, Cabadak H, Gören MZ. The change in muscarinic receptor subtypes in different brain regions of rats treated with fluoxetine or propranolol in a model of post-traumatic stress disorder. Behav Brain Res 2012;232:124-129.

22. LeDoux JE, Iwata J, Cicchetti P, Reis DJ. Different projections of the central amygdaloid nucleus mediate autonomic and behavioral correlates of conditioned fear. I Neurosci 1988;8: 2517-2529.

23. Fendt M, Fanselow MS. The neuroanatomical and neurochemical basis of conditioned fear. Neurosci Biobehav Rev 1999;23:743-760.

24. Rodrigues SM, LeDoux JE, Sapolsky RM. The influence of 
stress hormones on fear circuitry. Annu Rev Neurosci 2009; 32:289-313.

25. Blanchard RJ, Yang M, Li Cl, Gervacio A, Blanchard DC. Cue and context conditioning of defensive behaviors to cat odor stimuli. Neurosci Biobehav Rev 2001;25:587-595.

26. Roelofs K. Freeze for action: neurobiological mechanisms in animal and human freezing. Philos Trans R Soc Lond B Biol Sci 2017;372:20160206.

27. Sarıdoğan GE, Aykaç A, Cabadak H, Cerit C, Çalışkan M, Gören MZ. D-Cycloserine acts via increasing the GluN1 protein expressions in the frontal cortex and decreases the avoidance and risk assessment behaviors in a rat traumatic stress model. Behav Brain Res 2015;293:227-233.

28. Selken J, Nichols DE. Alpha1-adrenergic receptors mediate the locomotor response to systemic administration of (+/-)-3,4methylenedioxymethamphetamine (MDMA) in rats. Pharmacol Biochem Behav 2007;86:622-630.

29. Aspesi D, Pinna G. Animal models of post-traumatic stress disorder and novel treatment targets. Behav Pharmacol 2019;30: 130-150.

30. Matar MA, Zohar J, Kaplan Z, Cohen H. Alprazolam treatment immediately after stress exposure interferes with the normal HPA-stress response and increases vulnerability to subsequent stress in an animal model of PTSD. Eur Neuropsychopharmacol 2009; 19:283-295.

31. Sonne C, Carlsson J, Bech P, Elklit A, Mortensen EL. Treatment of trauma-affected refugees with venlafaxine versus sertraline combined with psychotherapy - a randomised study. BMC Psychiatry 2016;16:383.

32. Sutherland SM, Davidson JR. Pharmacotherapy for post-traumatic stress disorder. Psychiatr Clin North Am 1994;17:409423.

33. Frijling J, Olff M, van Zuiden M. Pharmacological prevention of PTSD: current evidence for clinical practice. Psychiatr Ann 2019;49:307-313.

34. Gray JA. The neuropsychology of anxiety. Br J Psychol 1978;69:417-434.

35. Davis M, Redmond DE Jr, Baraban JM. Noradrenergic agonists and antagonists: effects on conditioned fear as measured by the potentiated startle paradigm. Psychopharmacology (Berl) 1979;65:111-118.

36. Redmond DE Jr, Huang YH. Current concepts. II. New evidence for a locus coeruleus-norepinephrine connection with anxiety. Life Sci 1979;25:2149-2162.

37. Cohen H, Kaplan Z, Koresh O, Matar MA, Geva AB, Zohar J. Early post-stressor intervention with propranolol is ineffective in preventing posttraumatic stress responses in an animal model for PTSD. Eur Neuropsychopharmacol 2011;21:230240.

38. Rauch SL, Shin LM, Phelps EA. Neurocircuitry models of posttraumatic stress disorder and extinction: human neuroimaging research--past, present, and future. Biol Psychiatry 2006;60:376-382.
39. Aubry AV, Serrano PA, Burghardt NS. Molecular mechanisms of stress-induced increases in fear memory consolidation within the amygdala. Front Behav Neurosci 2016;10:191.

40. Lubbe WF, Hodge JV. Combined alpha- and beta-adrenoceptor antagonism with prazosin and oxprenolol in control of severe hypertension in pregnancy. N Z Med J 1981;94:169172.

41. Digne-Malcolm H, Frise MC, Dorrington KL. How do antihypertensive drugs work? Insights from studies of the renal regulation of arterial blood pressure. Front Physiol 2016;7: 320.

42. Kung S, Espinel Z, Lapid MI. Treatment of nightmares with prazosin: a systematic review. Mayo Clin Proc 2012;87:890900.

43. Lazzaro SC, Hou M, Cunha C, LeDoux JE, Cain CK. Antagonism of lateral amygdala alpha 1-adrenergic receptors facilitates fear conditioning and long-term potentiation. Learn Mem 2010;17:489-493.

44. Jones LS, Gauger LL, Davis JN. Anatomy of brain alpha 1-adrenergic receptors: in vitro autoradiography with [125I]-heat. J Comp Neurol 1985;231:190-208.

45. Domyancic AV, Morilak DA. Distribution of alpha1A adrenergic receptor $m R N A$ in the rat brain visualized by in situ hybridization. J Comp Neurol 1997;386:358-378.

46. Pitkänen A, Pikkarainen M, Nurminen N, Ylinen A. Reciprocal connections between the amygdala and the hippocampal formation, perirhinal cortex, and postrhinal cortex in rat. a review. Ann N Y Acad Sci 2000;911:369-391.

47. Aston-Jones G, Cohen JD. Adaptive gain and the role of the locus coeruleus-norepinephrine system in optimal performance. J Comp Neurol 2005;493:99-110.

48. Lucas EK, Wu WC, Roman-Ortiz C, Clem RL. Prazosin during fear conditioning facilitates subsequent extinction in male C57BI/6N mice. Psychopharmacology (Berl) 2019;236:273279.

49. Brunet A, Orr SP, Tremblay J, Robertson K, Nader K, Pitman RK. Effect of post-retrieval propranolol on psychophysiologic responding during subsequent script-driven traumatic imagery in post-traumatic stress disorder. J Psychiatr Res 2008; 42:503-506.

50. Orr SP, Milad MR, Metzger LJ, Lasko NB, Gilbertson MW, Pitman RK. Effects of beta blockade, PTSD diagnosis, and explicit threat on the extinction and retention of an aversively conditioned response. Biol Psychol 2006;73:262-271.

51. Pitman RK, Sanders KM, Zusman RM, Healy AR, Cheema F, Lasko NB, et al. Pilot study of secondary prevention of posttraumatic stress disorder with propranolol. Biol Psychiatry 2002;51:189-192.

52. Pitman RK, Delahanty DL. Conceptually driven pharmacologic approaches to acute trauma. CNS Spectr 2005;10:99106.

53. Naitou K, Shiina T, Kato K, Nakamori H, Sano Y, Shimizu Y. Colokinetic effect of noradrenaline in the spinal defecation 
center: implication for motility disorders. Sci Rep 2015;5: 12623.

54. Fanselow MS, Poulos AM. The neuroscience of mammalian associative learning. Annu Rev Psychol 2005;56:207-234.

55. Paré D, Quirk GJ, Ledoux JE. New vistas on amygdala networks in conditioned fear. J Neurophysiol 2004;92:1-9.

56. McGaugh JL. The amygdala modulates the consolidation of memories of emotionally arousing experiences. Annu Rev Neurosci 2004;27:1-28.

57. Quirk GJ, Mueller D. Neural mechanisms of extinction learning and retrieval. Neuropsychopharmacology 2008;33:56-72.

58. LeDoux J. The amygdala. Curr Biol 2007;17:R868-R874.

59. Swanson LW. The amygdala and its place in the cerebral hemisphere. Ann N Y Acad Sci 2003;985:174-184.

60. Quirk GJ, Garcia R, González-Lima F. Prefrontal mechanisms in extinction of conditioned fear. Biol Psychiatry 2006;60: 337-343.

61. Rosenkranz JA, Moore H, Grace AA. The prefrontal cortex regulates lateral amygdala neuronal plasticity and responses to previously conditioned stimuli. J Neurosci 2003;23:1105411064.

62. Sotres-Bayon F, Bush DE, LeDoux JE. Emotional perseveration: an update on prefrontal-amygdala interactions in fear extinction. Learn Mem 2004; 11:525-535.

63. Goldstein DS. Catecholamines and stress. Endocr Regul 2003;37:69-80
64. McCarty R, Gold PE. Catecholamines, stress, and disease: a psychobiological perspective. Psychosom Med 1996;58: 590-597.

65. Vermetten E, Bremner JD. Circuits and systems in stress. II. Applications to neurobiology and treatment in posttraumatic stress disorder. Depress Anxiety 2002;16:14-38.

66. Tully K, Li Y, Tsvetkov E, Bolshakov VY. Norepinephrine enables the induction of associative long-term potentiation at thalamo-amygdala synapses. Proc Natl Acad Sci U S A 2007; 104:14146-14150.

67. Furey ML, Khanna A, Hoffman EM, Drevets WC. Scopolamine produces larger antidepressant and antianxiety effects in women than in men. Neuropsychopharmacology 2010;35: 2479-2488.

68. Gören Z, Aslan N, Berkman K, Oktay S, Onat F. The role of amygdala and hypothalamus in GABAA antagonist bicuculline-induced cardiovascular responses in conscious rats. Brain Res 1996;722:118-124.

69. Aslan N, Gören Z, Ozkutlu U, Onat F, Oktay S. Modulation of the pressor response elicited by carbachol and electrical stimulation of the amygdala by muscarinic antagonists in conscious rats. Br J Pharmacol 1997; 121:35-40.

70. Gören MZ, Onat F, Berkman K. Participation of NMDA and kainate receptors of paraventricular nucleus in cardiovascular responses to glutamate receptor agonist. Eur J Pharmacol 2000;388:77-84. 